\title{
A twisted monomeric perylenediimide electron acceptor for efficient organic solar cells
}

\author{
Yunhao Cai ${ }^{1}$, Xieyou Guo ${ }^{1}$, Xiaobo Sun ${ }^{1 *}$, Donghui $\mathrm{Wei}^{2}$, Mingming $\mathrm{Yu}^{2}$, Lijun Huo ${ }^{1 *}$ \\ and Yanming Sun ${ }^{1 *}$
}

\begin{abstract}
Perylenediimide (PDI)-based materials exhibit great potential as non-fullerene acceptors in bulk-heterojunction (BHJ) organic solar cells (OSCs). Recent investigations have revealed that PDI molecules with a twisted structure could disrupt aggregation of perylene unit. Here, we present a PDI monomer via bay-substitutions with four fused naphthalene units by three-step reactions, named TN-PDI. The introduction of four fused naphthalene rings into the bay positions of PDI unit leads to a strong steric hindrance with a twist angle of $33^{\circ}$ between the two PDI subplanes. Blended with a wide-band gap polymer donor (PDBT-T1), the TN-PDI based non-fullerene solar cells show power conversion efficiency (PCE) of 3.0\%. Our results indicate that the bay-substitutions with fused aromatic substitutions could be an efficient approach to develop monomeric PDI acceptors.
\end{abstract}

Keywords: organic solar cells, non-fullerene electron acceptors, perylene diimide, monomer

\section{INTRODUCTION}

Solution-processed bulk-heterojunction (BHJ) organic solar cells (OSCs) have emerged as one of the next-generation energy resources to meet the worldwide urgent energy demand in virtue of their merits in light weight, low fabrication cost and the capability to build on the plastics and printing manufactures [1-7]. Among various materials used for acceptors, fullerene derivatives act as the protagonists of electron acceptors, which lead the power conversion efficiencies (PCEs) to $11 \%$ for single junction OSCs [8-12]. Despite the achievements of fullerene derivatives in laboratory scale devices, the high-cost production, inflexibility in chemical modification, and weak light absorption in the visible region of fullerenes hamper their practical applications [13-16]. To this end, design and synthesis of or- ganic fused acceptors have being considered as vital alternates to the fullerene counterparts in terms of their tunable energy level, broad absorption, and chemical robustness [17-19]. Recently, several excellent polymer/non-fullerene systems have leaded to the high PCEs up to $9 \%$, which indicates that non-fullerene OSCs have enormous potential to approach performance similar to that of fullerene-based solar cells [20-23].

Perylene diimide (PDI) derivatives are widely used as the electron acceptor in OSCs due to their excellent thermal and chemical stabilities, strong electron-accepting abilities, and high electron mobilities [24,25]. However, in the initial stage, PDI derivatives suffer from over-strong propensity of aggregation, leading to the formation of large crystalline domains [26-29]. Moreover, some PDI derivatives intend to form excimers that perform as traps for excitation energy which severely hinder the efficiency of exciton splitting and the further performance of the OSCs [30-33]. Considerable effort has been dedicated to design and synthesize PDI-based acceptors with twisted structures in order to weaken aggregation and restrict crystalline of molecules [34-39]. PDI monomers are alternative non-fullerene acceptors. Functionalized monomeric PDI derivatives were generally synthesized with alkyl-chain on the imide position or aliphatic or aromatic substituent on the bay-position [40-45]. The modification on the bay region can be of tremendous assistance to make the perylene core twisted, impede intermolecular interactions, and adjust the energy levels of the materials potentially [46-48]. Recently, we have reported a PDI monomer (TP-PDI), in which four phenyl groups are appended to the bay positions of PDI unit. OSCs based on TP-PDI acceptor showed a record

\footnotetext{
${ }^{1}$ Heeger Beijing Research and Development Center, School of Chemistry and Environment, Beihang University, Beijing 100191, China

${ }^{2}$ The College of Chemistry and Molecular Engineering, Zhengzhou University, Zhengzhou 450001, China

${ }^{*}$ Corresponding authors (emails: sunxb@buaa.edu.cn (Sun X); huolijun@buaa.edu.cn (Huo L); sunym@buaa.edu.cn (Sun Y))
} 
PCE of $4.1 \%$ for monomeric PDI based polymer solar cells [45]. The high performance of TP-PDI inspired us subsequently to develop its analogue to study the relationship between photovoltaic properties and twisted molecular structures for PDI acceptors.

Herein, we reported a non-fullerene acceptor 1,6,7,12tetra-naphthaleneyl-perylenediimide (TN-PDI), in which four fused naphthalene units are inserted to the bay positions of PDI core. The incorporation of naphthalene units could afford a twisted configuration and provide a solution for inhibiting aggregation tendency and tuning the phase separation in as-casted film. Moreover, this PDI monomer could be simply synthesized in three steps and purified on a large scale [49]. TN-PDI possesses high lowest unoccupied molecular orbital (LUMO) level which leads to an impressive an open-circuit voltage $\left(V_{\mathrm{oc}}\right)$, broad absorption in visible spectrum and complements well with the donor material. By incorporating a wide band gap polymer PDBT-T1 [50] with the monomer, an initial PCE of $3.0 \%$ was achieved with a $V_{\text {oc }}$ of $0.95 \mathrm{~V}$, short-circuit current density $\left(J_{\mathrm{sc}}\right)$ of $7.70 \mathrm{~mA} \mathrm{~cm}^{-2}$, fill factor $(F F)$ of 0.41 .

\section{EXPERIMENTAL SECTION}

\section{Materials}

3,4,9,10-Perylenetetracarboxylic dianhydride, 2-ethylhexylamine, 1-naphthaleneboronic acid, tetrakis(triphenylphosphine)palladium, cesium fluoride, and silver(I) oxide were purchased from Acros. The wide-bandgap polymer PDBT-T1 is previously reported by our group [50]. Regular chemical reagents and solvents were obtained from Beijing Chemical Plant. Solvents for reactions and photophysical measurements, such as $N, N^{\prime}$-dimethylformamide (DMF), tetrahydrofuran (THF), and dichloromethane $\left(\mathrm{CH}_{2} \mathrm{Cl}_{2}\right)$, were all distilled after dehydration according to conventional methods.

\section{General}

Mass spectra were recorded on an AEI-MA50-MS spectrometer for EI-MS. MALDI-TOF spectra were recorded on a Bruker BIFLEX III instrument. ${ }^{1} \mathrm{H}$ and ${ }^{13} \mathrm{C}$ NMR spectra were recorded on a Bruker AVANCE $400 \mathrm{MHz}$ spectrometer using $\mathrm{CDCl}_{3}$ as the solvent. Thermogravimetric analyses (TGA) were performed on a NETZSCH STA 409 under $\mathrm{N}_{2}$ flow at a heating rate of $20^{\circ} \mathrm{C} \mathrm{min}^{-1}$. UV-vis absorption spectra were obtained with SHIMADZU UV-2600. Theoretical calculations using density functional theory (DFT) were performed using the Gaussian03 package at the B3LYP level of theory with a basis set of 6-31G(d). Atomic force microscopy (AFM) images were obtained using a NanoMan VS microscope in the tapping mode. Cyclic voltammetric ( $\mathrm{CV}$ ) measurements were performed in a conventional three-electrode cell using a Pt button as working electrode of $2 \mathrm{~mm}$ in diameter, a $\mathrm{Pt}$ wire as counter electrode, and a $\mathrm{Ag} / \mathrm{Ag}^{+}$electrode as reference electrode on a computer-controlled $\mathrm{CHI}-660 \mathrm{E}$ electrochemical workstation at room temperature. The compound tetrabutylammonium hexafluorophosphate $\left(\mathrm{Bu}_{4} \mathrm{NPF}_{6}\right)\left(0.1 \mathrm{~mol} \mathrm{~L}^{-1}\right)$ is used as a supporting electrolyte. The energy levels were calculated using the ferrocene $\left(E_{\mathrm{FOC}}\right)$ value of $4.8 \mathrm{eV}$ as the standard: $E_{\mathrm{HOMO}}=-\left(E_{\mathrm{ox}}+\right.$ 4.80) (eV) (highest occupied molecular orbital (HOMO)), $E_{\mathrm{LUMO}}=-\left(E_{\mathrm{red}}+4.80\right)(\mathrm{eV})$.

\section{Synthesis}

Compound 1 (1,6,7,12-tetrabromoperylene-3,4,9,10tetracarboxylic acid bisanhydride) and compound $2 \quad\left(N, N^{\prime}\right.$-Di(2-ethylhexyl)-1,6,7,12-tetra-bromoperylene-3,4,9,10-tetra-carboxylic acid bisimide) were synthesized as reported in our previous work [49].

Compound TN-PDI (N,N'-di(2-ethylhexyl)-1,6,7,12tetranaphthaleneperylene-3,4,9,10-tetracarboxylic acid bisimide): compound 2 (626 $\mathrm{mg}, 0.72 \mathrm{mmol}), 1$-naphthaleneboronic ( $528 \mathrm{mg}, 4.32 \mathrm{mmol}$ ), cesium fluoride ( 880 $\mathrm{mg}, 5.76 \mathrm{mmol}$ ) and silver(I) oxide $(736 \mathrm{mg}, 3.2 \mathrm{mmol})$ were added to a three-neck flask. After the flask was degassed with nitrogen, tetrakis(triphenylphosphine)palladium ( $83 \mathrm{mg}, 0.072 \mathrm{mmol}$ ) was added with a gentle flow of nitrogen. $15 \mathrm{~mL}$ THF was added. Then, the flask was cooled to $-78^{\circ} \mathrm{C}$ and further evacuated and backfilled with nitrogen three times. The reaction mixture was stirred at $80^{\circ} \mathrm{C}$ for $24 \mathrm{~h}$ with vigorous stirring. After cooled to room temperature, the crude product was purified by flash column chromatography $\left(\mathrm{SiO}_{2}\right.$, toluene) to give 1,6,7,12-tetraphenylperylene bisimide as a dark purple solid. Yield: 29\%. ${ }^{1} \mathrm{H}$ NMR (400 $\mathrm{MHz}, \mathrm{CDCl}_{3}, \mathrm{ppm}$, $\left.25^{\circ} \mathrm{C}\right): \delta=8.43-8.46(4 \mathrm{H}, \mathrm{m}$, perylene- $\mathrm{H}), 7.73-7.75(4 \mathrm{H}$, m, naph-H), 7.43-7.45 (8H, br, naph-H), 7.09 (4H, s, br, naph-H), $6.82(4 \mathrm{H}, \mathrm{s}, \mathrm{br}$, naph-H), $6.66(8 \mathrm{H}, \mathrm{m}$, naph-H), 4.16-4.18 (4H, d, N-CH-), 2.00 (2H, m, -CH-), 1.33-1.44 (18H, m, -CH2-), 0.85-1.05 (12H, m, $-\mathrm{CH} 2-) .{ }^{13} \mathrm{C}$ NMR $\left(\mathrm{CDCl}_{3}, 25^{\circ} \mathrm{C}\right): \delta=164.39(\mathrm{C}=\mathrm{O}), 142.58,137.94$, $134.78,134.37,132.25,131.98,129.95,128.24,127.78$, $127.16,126.67,126.27,122.65,44.44,38.30,32.06,31.12$, $30.91,29.83,29.22,28.74,24.49,24.26,23.25,22.82,14.30$, 11.01, 10.66. MALDI-TOF-MS: calcd. for $\mathrm{C}_{80} \mathrm{H}_{66} \mathrm{~N}_{2} \mathrm{O}_{4}$ 1119.39; found: 1119.5. Elemental analysis calcd. (\%) for $\left(\mathrm{C}_{80} \mathrm{H}_{66} \mathrm{~N}_{2} \mathrm{O}_{4}\right)$ : C, 85.84; $\mathrm{H}, 5.94 ; \mathrm{N}, 2.50$; found: $\mathrm{C}, 85.51$; 


\section{H, 5.91; N, 2.52 .}

\section{Device fabrication and characterization}

BHJ OSCs were fabricated on indium tin oxides (ITO)coated glass substrates, which were first cleaned in an ultrasonic bath, sequentially in detergent, water, acetone, and isopropyl alcohol. After pretreated with UV-ozone for 20 mins, $\mathrm{ZnO}$ precursor solution was spin-cast onto the ITO substrate and baked at $230^{\circ} \mathrm{C}$ for $20 \mathrm{~min}$. Active layer solution containing a mixture of PDBT-T1:TN-PDI(with or without $0.25 \% \mathrm{DIO}, 50: 50 \mathrm{w} / \mathrm{w}$ )in dichlorobenzene at a total solids concentration of $20 \mathrm{mg} \mathrm{mL}^{-1}$ was spin casted at $1300 \mathrm{rpm}$ for $90 \mathrm{~s}$. Before transferred into a thermal evaporator, the samples were annealed at $90^{\circ} \mathrm{C}$ for 5 mins to achieve an optimized film. Then, $\mathrm{MoO}_{x}(\approx 6 \mathrm{~nm})$ and $\mathrm{Al}$ $(\approx 100 \mathrm{~nm})$ layers at the vacuum condition of $8 \times 10^{-5} \mathrm{~Pa}$ were deposited in the evaporator. The active area of the devices was $4.50 \mathrm{~mm}^{2}$. Current density-voltage $(J-V)$ characteristics were measured by using a Keithley 2400 Source Measure Unit. Solar cell performance was characterized by an Air Mass 1.5 Global (AM 1.5 G) solar simulator (Class AAA solar simulator, Model 94063A, Oriel) with an irradiation intensity of $100 \mathrm{~mW} \mathrm{~cm}^{-2}$, which was measured by a calibrated silicon solar cell and a readout meter (Model 91150V, Newport). Incident photon-to-current conversion efficiency (IPCE) spectra were measured by a QEX10 Solar Cell IPCE measurement system (PV measurements, Inc.).

\section{RESULTS AND DISCUSSION}

\section{Synthesis}

As shown in Scheme 1, TN-PDI was synthesized in three steps: first, compound $\mathbf{1}$ was synthesized by treatment of perylene bisanhydride with $\mathrm{Br}_{2}$ in the mixture of sulfuric acid and fuming sulfuric acid with crude yield is as good as $96 \%$. Then, compound 2 was functionalized by 2 -ethylhexylamine at $\mathrm{N}$-position in propionic acid. Finally, the four bromines in the bay position of compound 2 were successfully substituted by naphthaleneboronic to construct TN-PDI through fluoride ion-mediated and $\mathrm{Ag}_{2} \mathrm{O}$-promoted Suzuki coupling reaction [44]. The compound exhibits good solubility in common organic solvents such as $\mathrm{CH}_{2} \mathrm{Cl}_{2}$, THF, and toluene at room temperature, which provides convenience for purification and full characterizations. Such solubility is mainly due to both the branched alkyl side chains and the twisted molecular skeleton. For the large molecular weight of TN-PDI, a MALDI-TOF-MS measurement (Mw.1119.5 as found) is employed to characterize the structure and molecular weight directly. Thermogravimetric analysis (TGA) was utilized to evaluate the thermal property under a nitrogen atmosphere at a heating rate of $20^{\circ} \mathrm{C} \mathrm{min}{ }^{-1}$. TN-PDI shows great thermal stability with $5 \%$ weight loss temperature at $446^{\circ} \mathrm{C}$ (see Fig. S1).

\section{Theoretical simulation of TN-PDI}

To gain a deeper insight into the electronic distribution and geometrical configuration of TN-PDI, we performed DFT calculations at B3LYP/6-31G(d) level. The corresponding electron distributions of HOMO and LUMO of the ground state optimized structures are shown in Fig. 1a. For the HOMO level of TN-PDI, more electrons are distributed around the PDI unit, with only a slight influence from the

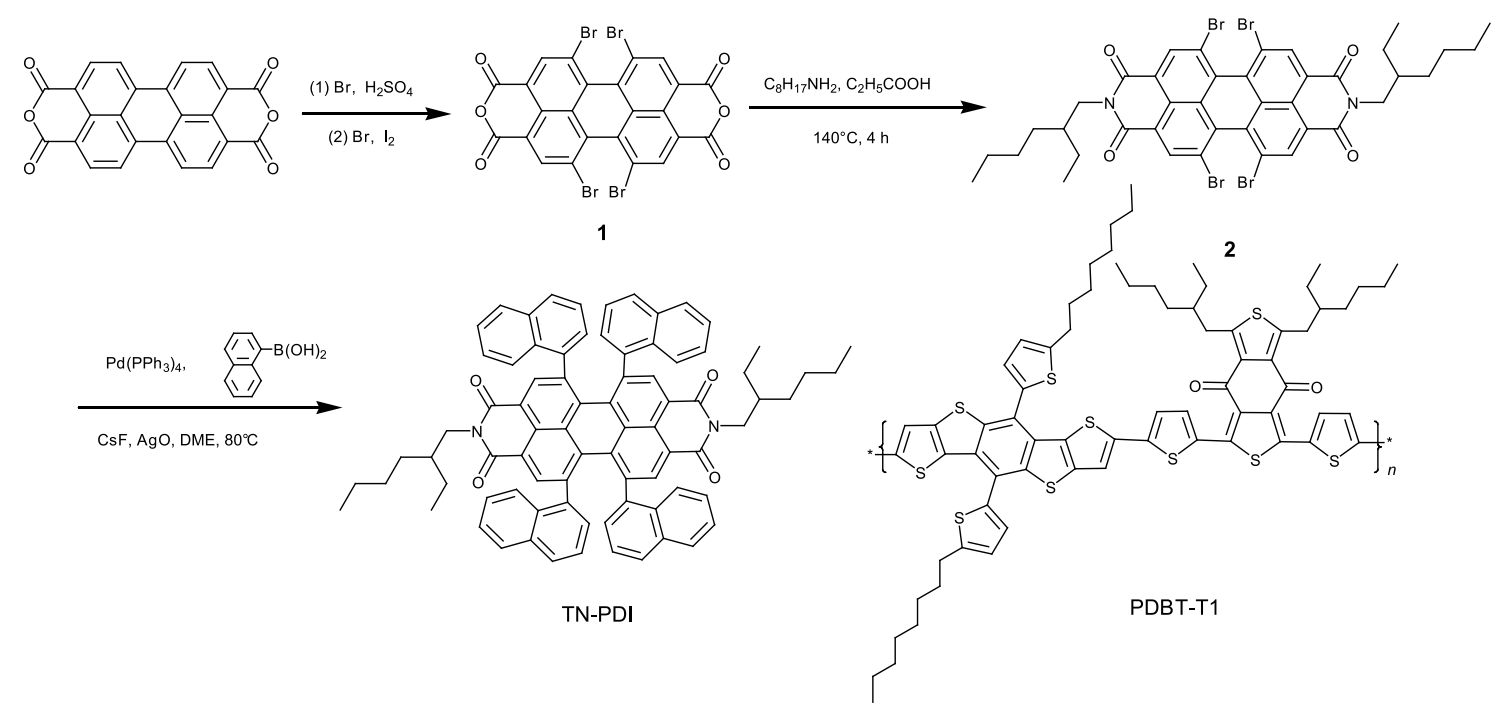

Scheme 1 Synthetic route of TN-PDI and the chemical structure of PDBT-T1. 

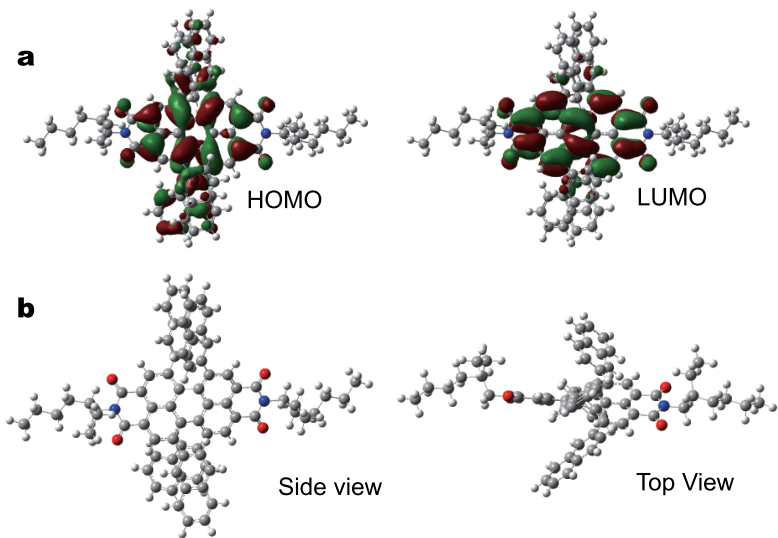

Figure 1 Optimized geometries of TN-PDI by DFT at the B3LYP/ 6-31G(d) level: (a) frontier molecular orbitals, (b) side view and top view of the molecular model.

naphthalene unit. On transition to the LUMO level, the molecular orbital of the PDI unit is dominant. Fig. 1b shows the side view and top view of the geometrical configuration of TN-PDI. The pristine PDI unit is completely planar without any substituent at the bay positions. For TN-PDI, PDI was functionalized via bay-substitution with fused naphthalene, and the determined twisted angle between the two subplanes of PDI is about $33^{\circ}$ (Fig. S2), due to strong steric repulsion of the naphthalene units at the bay positions. And, the dihedral angle between the plane of the naphthalene unit and the PDI is about $42^{\circ}$ (Fig. S2). Therefore, the twisted structure will reduce the tendency of aggregation of PDI unit in the solid state, which leads to a better performance of optoelectronic devices.

\section{Optical properties}

The UV-vis absorption spectra of TN-PDI were measured in solution and thin film as presented in Fig. 2a. It can be seen that TN-PDI (in chloroform, $10^{-6} \mathrm{~mol} \mathrm{~L}^{-1}$ ) exhibits a broad absorption spectrum with two peaks at 528 and $613 \mathrm{~nm}$. Compared with the absorption spectrum in solution, the spectrum in thin film of TN-PDI shows a similar profile with only a relatively small shift of $5 \mathrm{~nm}$, indicating weak molecular aggregation and intermolecular interaction in the solid state [51]. The optical feature could be assigned to the twisted structure of the perylene unit supported by the theoretical calculations. For the BHJ OSCs constructed with TN-PDI as acceptor, we chose a wide band-gap polymer PDBT-T1 (shown in scheme 1) as the electron donor. As illustrated in Fig. 2b, the main absorption of PDBT-T1 is in the range of $550-700 \mathrm{~nm}$, which complements the weak absorption of TN-PDI in this region, and should be beneficial for charge generation inside the devices. Finally, a broad absorption covering the visible range of 400-700 nm was observed for PDBT-T1: TN-PDI blend film $(1: 1, w / w)$, which may suggest a better $J_{\text {sc }}$ for the OSCs.

\section{Electrochemical properties}

The electrochemical property of TN-PDI was investigated by $\mathrm{CV}$, as shown in Fig. 3a. When potential cycling was applied, TN-PDI exhibits electrochemically stable. The CV curve was recorded $v s$. the potential of $\mathrm{Ag} / \mathrm{Ag}^{+}$reference electrode. In the cathodic scan region, TN-PDI rises to one reversible reduction waves, which reflects electron reductive process of the perylene cores. In the anodic scan region, the irreversible oxidation peak was observed at ca. $1.35 \mathrm{~V}$, which is attributed to the oxidation of naphthalene moieties. The onset oxidation and reduction potentials are $0.80 /-0.80 \mathrm{~V} v s$. $\mathrm{Ag} / \mathrm{Ag}^{+}$electrode, so the HOMO and LUMO energies of TN-PDI are to be at -5.60 and -4.00 $\mathrm{eV}$, respecdtively. The energy level of PDBT-T1 is also displayed in Fig. 3b. The energy offset between the HOMO of PDBT-T1 $(-5.36 \mathrm{eV})$ and the LUMO of TN-PDI $(-4.00$ $\mathrm{eV})$ is $1.36 \mathrm{eV}$. As a consequence, a high $V_{\mathrm{oc}}$ is expected. The LUMO gap between the PDBT-T1 and TN-PDI is 0.57
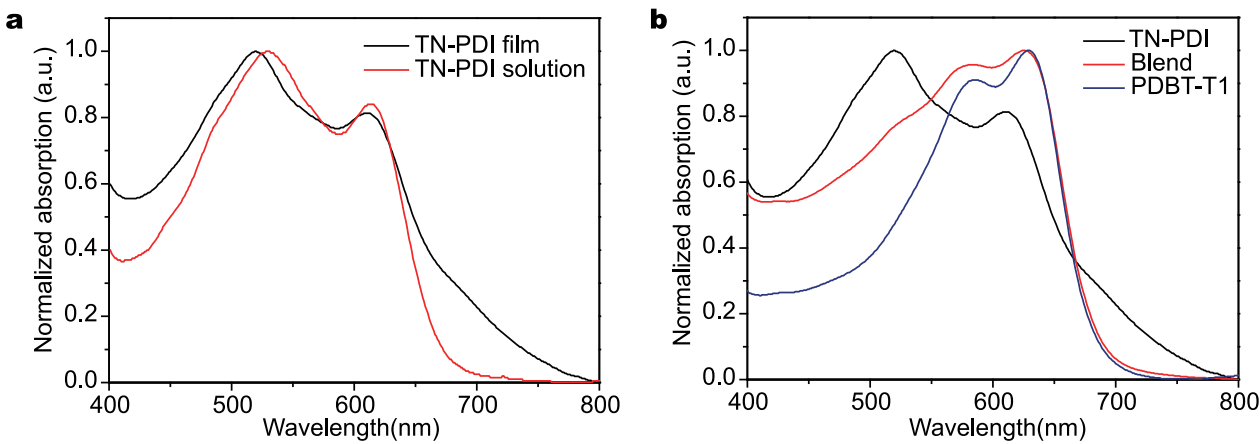

Figure 2 (a) Normalized UV-vis absorption spectra of neat TN-PDI in solution and thin film, (b) normalized thin-film absorption spectra of neat TN-PDI, PDBT-T1 and their composite $\left(1: 1 w / w\right.$, PDBT-T1 concentration is $\left.10 \mathrm{mg} \mathrm{mL}^{-1}\right)$. 

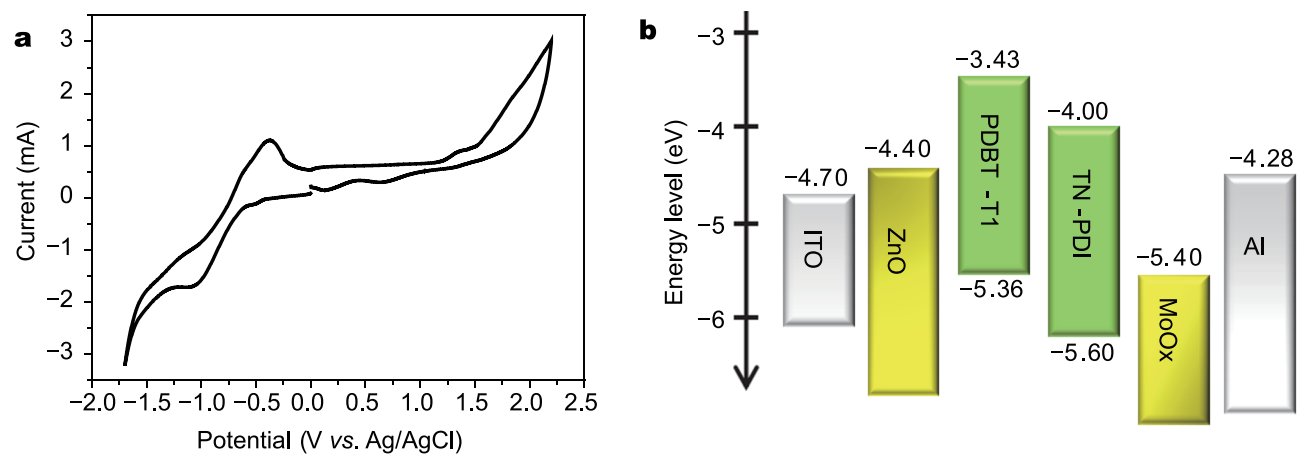

Figure 3 (a) CV plot of TN-PDI in thin film, (b) energy levels of all materials used in the solar cell device.

$\mathrm{eV}$, expected to be sufficient for efficient exciton dissociation.

\section{Photovoltaic properties}

To demonstrate the potential application of TN-PDI in OSCs, an inverted structure of ITO/ZnO/ PDBT-T1:TN$\mathrm{PDI} / \mathrm{MoO}_{x} / \mathrm{Al}$ was used in this work, sol-gel-derived $\mathrm{ZnO}$ is the electron transport layer [52], and $\mathrm{MoO}_{x}$ is functioned as the hole transport layer. As known, weight ratios of donor and acceptor in active layers play important roles on the performance of OSCs. Thus, three different weight ratios at 1.5:1, 1.1 and 1:1.5 $(w / w)$ were performed for the PBDT-T1:TN-PDI blend films. The corresponding photovoltaic parameters were summarized in Table 1 . With weight ratios decreasing, there are almost no change for
$V_{\mathrm{oc}}$, which are all above $0.9 \mathrm{~V}$. But, in terms of $J_{\mathrm{sc}}$ and $F F$ parameters, the devices show big difference with different weight ratios. Thus, the optimal ratio of the donor and acceptor is found to be 1:1. It is known that photovoltaic properties are greatly affected by the morphology of the active layers. 1,8-diiodooctane (DIO) was used to modify the morphology so as to further improve the cell performance (as shown in Table 2). The current density-voltage $(J-V)$ curves of the devices fabricated with optimal conditions under simulated AM 1.5 G irradiation with intensity of $100 \mathrm{~mW} \mathrm{~cm}^{-2}$ are shown in Fig. 4a. When $0.25 \%$ DIO was added, $J_{\mathrm{sc}}$ increased from $6.94 \mathrm{~mA} \mathrm{~cm}{ }^{-2}$ to $7.70 \mathrm{~mA}$ $\mathrm{cm}^{-2}, F F$ increased to 0.41 , and an improved PCE of $3.0 \%$ was achieved. Compared with the reported PCEs of PDI monomer-based solar cells, this initial PCE is much higher
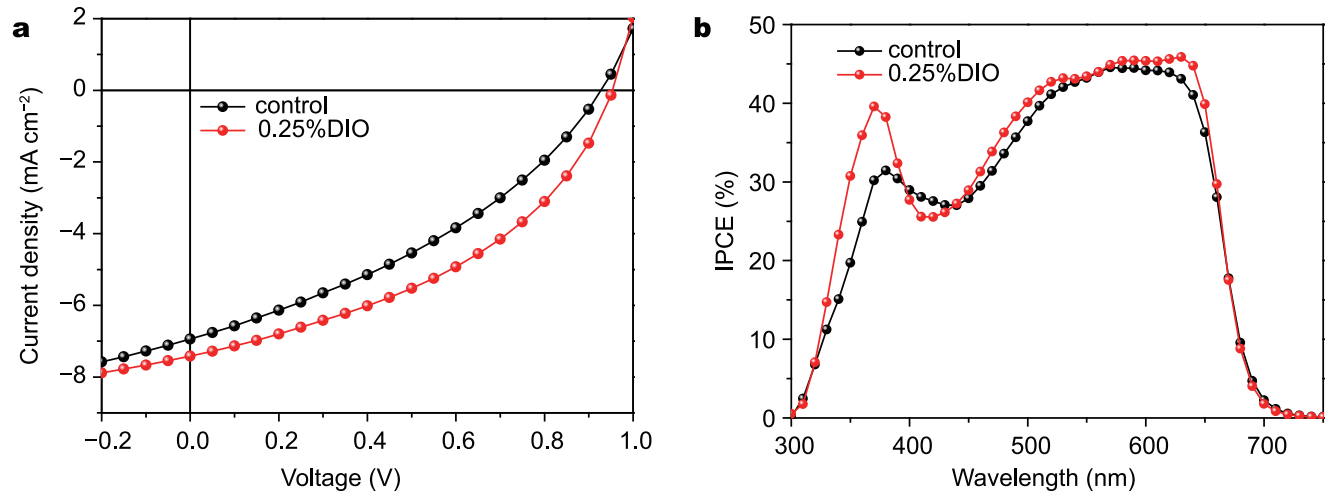

Figure 4 (a) $J-V$ curves of OSCs with an inverted structure based on PDBT-T1:TN-PDI solar cells with/without DIO under simulated AM 1.5G irradiation $\left(100 \mathrm{~mW} \mathrm{~cm}^{-2}\right)$, and (b) the corresponding IPCE spectra.

Table 1 Photovoltaic performance of solar cells based on different weight ratios of PBDT-T1:TN-PDI in an inverted structure under the illumination of AM1.5G, $100 \mathrm{~mW} \mathrm{~cm}{ }^{-2}$

\begin{tabular}{cccccc}
\hline Weight ratios $(w / w)$ & $V_{\text {oc }}[\mathrm{V}]$ & $J_{\text {sc }}\left[\mathrm{mA} \mathrm{cm}^{-2}\right]$ & $F F[\%]$ & PCE $^{\mathrm{a}}[\%]$ & PCE $_{\max }[\%]$ \\
\hline $1.5: 1.0$ & $0.930 \pm 0.004$ & $6.51 \pm 0.09$ & $0.35 \pm 0.02$ & $2.12 \pm 0.16$ & 2.28 \\
$1: 1$ & $0.947 \pm 0.003$ & $7.52 \pm 0.18$ & $0.40 \pm 0.01$ & $2.85 \pm 0.15$ & 3.00 \\
$1.0: 1.5$ & $0.930 \pm 0.002$ & $6.60 \pm 0.13$ & $0.36 \pm 0.03$ & $2.20 \pm 0.25$ & 2.45 \\
\hline
\end{tabular}

a) The average PCE value was calculated from five devices for each condition. 
Table 2 Photovoltaic performance of solar cells based on PBDT-T1:TN-PDI $(1: 1, w / w)$ with different DIO additive contents in an inverted structure under the illumination of AM1.5G, $100 \mathrm{~mW} \mathrm{~cm}^{-2}$

\begin{tabular}{ccccc}
\hline DIO $[v / v \%]$ & $V_{\text {oc }}[\mathrm{V}]$ & $J_{\text {sc }}\left[\mathrm{mA} \mathrm{cm}^{-2}\right]$ & $F F[\%]$ & PCE ${ }^{\mathrm{a}}[\%]$ \\
0 & $0.950 \pm 0.001$ & $6.87 \pm 0.07$ & $0.35 \pm 0.01$ & $2.28 \pm 0.11$ \\
0.25 & $0.947 \pm 0.003$ & $7.52 \pm 0.18$ & $0.40 \pm 0.01$ & 2.38 \\
0.50 & $0.937 \pm 0.007$ & $6.97 \pm 0.10$ & $0.41 \pm 0.01$ & 3.00 \\
2.80 & $2.68 \pm 0.12$ &
\end{tabular}

a) The average PCE value was calculated from five devices for each condition.

than that value reported from the two bay-positions substituted PDI monomer-based solar cells [40-43], and is close to the top values of the PDI monomer-based non-fullerene cells $[44,45]$.

Fig. $4 \mathrm{~b}$ shows the corresponding IPCE spectra of solar cells with or without DIO additive. The addition of DIO increases the IPCE obviously in $300-400 \mathrm{~nm}$. The maximum IPCE reached $46 \%$ at $630 \mathrm{~nm}$ for the champion cell. To make sure the accuracy of the $J_{\text {sc }}$ values measured from $J$ - $V$ curves, the photocurrent values from IPCE spectra was calculated. The calculated $J_{\mathrm{sc}}$ was $7.40 \mathrm{~mA} \mathrm{~cm} \mathrm{c}^{-2}$, entailing $5 \%$ mismatch with the value from $J-V$ measurement.

The bulk charge-transport properties of PDBT-T1:TNPDI blend films were investigated by the space-charge-limited current (SCLC) method. The device structures for electron-only measurements were ITO/Al/PDBT-T1:TNPDI/Al for optimized device. The electron mobility of the optimized device is $1.6 \times 10^{-3} \mathrm{~cm}^{2} \mathrm{~V}^{-1} \mathrm{~s}^{-1}$ (Fig. S4) and the electron mobility of neat TN-PDI film is $9.8 \times 10^{-4} \mathrm{~cm}^{2} \mathrm{~V}^{-1}$ $\mathrm{s}^{-1}$ (Fig. S5).

\section{Film morphology}

Influence of the solvent additive DIO on the morphology of PDBT-T1:TN-PDI blended films was investigated by AFM in the tapping mode (Fig. 5). The surface of the PDBT-T1:TN-PDI film without DIO shows relatively homogeneous and smooth surface morphology with a root mean square (RMS) roughness of $5.68 \mathrm{~nm}$. After the treatment of DIO additive, the film displays smaller crystalline grains and better mixed $\mathrm{BHJ}$ morphology with a RMS of $4.70 \mathrm{~nm}$. The more smooth and uniform morphology with the introduction of DIO implies better compatibility with the donor for TN-PDI, and leads to enhanced $J_{\text {sc }}$ and $F F$. The above discussions imply well that the molecule TN-PDI is an excellent acceptor candidate for efficient OSCs. Further work on optimized device is still under investigation.

\section{CONCLUSIONS}

In summary, a novel bay-substituted fused naphthalene functionalized PDI monomer (TN-PDI) was synthesized and successfully applied in BHJ OSCs. TN-PDI displayed
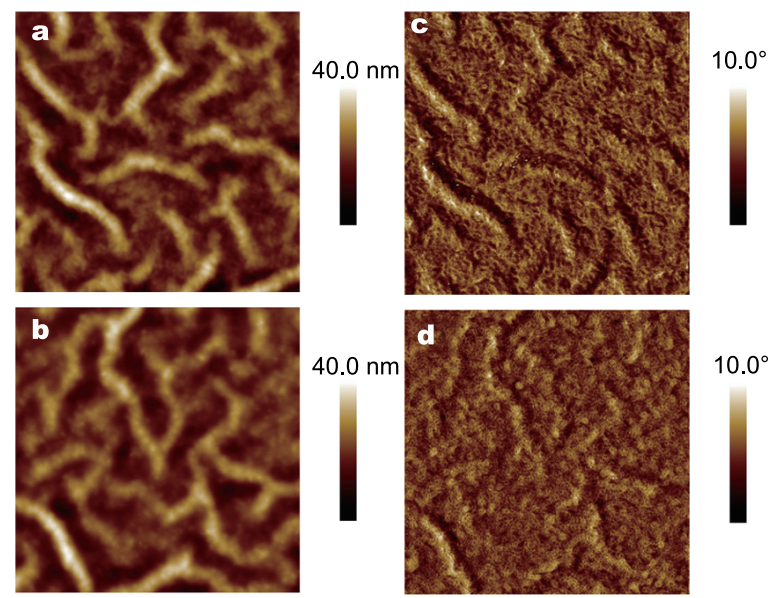

Figure 5 AFM topography image and phase image of PDBT-T1:TN-PDI blend films ( $\mathrm{a}$ and $\mathrm{c}$ ) without DIO additive, (b and d) with $0.25 \%$ DIO additive.

relatively strong absorption in the visible region, good miscibility with polymer donors. DFT calculations illuminate that the four bay-position substitutions introduce a twisting of the perylene skeleton, leading weak aggregation in the solid state. The solar cells with an inverted architecture show a PCE of $3.0 \%$. The results demonstrate that the bay-substitutions with fused aromatic substitutions could be an effective approach to develop monomeric PDI acceptors.

Received 30 April 2016; accepted 8 June 2016; published online 23 June 2016

1 Thompson BC, Fréchet JMJ. Polymer-fullerene composite solar cells. Angew Chem Int Ed, 2008, 47: 58-77

2 Son HJ, Carsten B, Jung IH, et al. Overcoming efficiency challenges in organic solar cells: rational development of conjugated polymers. Energy Environ Sci, 2012, 5: 8158-8170

3 Schwenn PE, Gui K, Nardes AM, et al. A small molecule non-fullerene electron acceptor for organic solar cells. Adv Energy Mater, 2011, 1: 73-81

4 Lin Y, Li Y, Zhan X. Small molecule semiconductors for high-efficiency organic photovoltaics. Chem Soc Rev, 2012, 41: 4245-4272

5 Li G, Zhu R, Yang Y. Polymer solar cells. Nat Photon, 2012, 6: 153-161

6 Heeger AJ. 25th anniversary article: bulk heterojunction solar cells: understanding the mechanism of operation. Adv Mater, 2014, 26: $10-28$ 
7 Dennler G, Scharber MC, Brabec CJ. Polymer-fullerene bulk-heterojunction solar cells. Adv Mater, 2009, 21: 1323-1338

8 He Z, Xiao B, Liu F, et al. Single-junction polymer solar cells with high efficiency and photovoltage. Nat Photon, 2015, 9: 174-179

9 Tang Z, Liu B, Melianas A, et al. A new fullerene-free bulk-heterojunction system for efficient high-voltage and high-fill factor solution-processed organic photovoltaics. Adv Mater, 2015, 27: 1900-1907

10 Yang YM, Chen W, Dou L, et al. High-performance multiple-donor bulk heterojunction solar cells. Nat Photon, 2015, 9: 190-198

11 Huo L, Liu T, Fan B, et al. Organic solar cells based on a 2D benzo[1,2-b:4,5- $b$ ']difuran-conjugated polymer with high-power conversion efficiency. Adv Mater, 2015, 27: 6969-6975

12 Yao $\mathrm{H}$, Zhao W, Zheng Z, et al. PBDT-TSR: a highly efficient conjugated polymer for polymer solar cells with a regioregular structure. J Mater Chem A, 2016, 4: 1708-1713

13 Lenes M, Shelton SW, Sieval AB, et al. Electron trapping in higher adduct fullerene-based solar cells. Adv Funct Mater, 2009, 19: 3002-3007

14 Anctil A, Babbitt CW, Raffaelle RP, et al. Material and energy intensity of fullerene production. Environ Sci Technol, 2011, 45: 2353-2359

15 Lin Y, Zhan X. Non-fullerene acceptors for organic photovoltaics: an emerging horizon. Mater Horiz, 2014, 1: 470-488

16 Eftaiha AF, Sun JP, Hill IG, et al. Recent advances of non-fullerene, small molecular acceptors for solution processed bulk heterojunction solar cells. J Mater Chem A, 2014, 2: 1201-1213

17 Nielsen CB, Holliday S, Chen HY, et al. Non-fullerene electron acceptors for use in organic solar cells. Acc Chem Res, 2015, 48: 2803-2812

18 Lin Y, Zhan X. Designing efficient non-fullerene acceptors by tailoring extended fused-rings with electron-deficient groups. Adv Energy Mater, 2015, 5: 1501063

19 Lin Y, Zhan X. Oligomer molecules for efficient organic photovoltaics. Acc Chem Res, 2016, 49: 175-183

20 Lin Y, Wang J, Zhang ZG, et al. An electron acceptor challenging fullerenes for efficient polymer solar cells. Adv Mater, 2015, 27: 1170-1174

21 Meng D, Sun D, Zhong C, et al. High-performance solution-processed non-fullerene organic solar cells based on selenophene-containing perylene bisimide acceptor. J Am Chem Soc, 2016, 138: 375-380

22 Lin $\mathrm{Y}, \mathrm{He} \mathrm{Q}$, Zhao F, et al. A facile planar fused-ring electron acceptor for as-cast polymer solar cells with $8.71 \%$ efficiency. J Am Chem Soc, 2016, 138: 2973-2976

23 Lin $\mathrm{Y}$, Zhao F, He Q, et al. High-performance electron acceptor with thienyl side chains for organic photovoltaics. J Am Chem Soc, 2016, 138: 4955-4961

24 Würthner F. Perylene bisimide dyes as versatile building blocks for functional supramolecular architectures. Chem Commun, 2004, 1564-1579

25 Zhan X, Facchetti A, Barlow S, et al. Rylene and related diimides for organic electronics. Adv Mater, 2011, 23: 268-284

26 Kozma E, Catellani M. Perylene diimides based materials for organic solar cells. Dyes Pigments, 2013, 98: 160-179

27 Zhan X, Tan Z, Domercq B, et al. A high-mobility electron-transport polymer with broad absorption and its use in field-effect transistors and all-polymer solar cells. J Am Chem Soc, 2007, 129: 7246-7247

28 Zhang X, Lu Z, Ye L, et al. A potential perylene diimide dimer-based acceptor material for highly efficient solution-processed non-fullerene organic solar cells with $4.03 \%$ Efficiency. Adv
Mater, 2013, 25: 5791-5797

29 Singh R, Giussani E, Mróz MM, et al. On the role of aggregation effects in the performance of perylene-diimide based solar cells. Organic Electrons, 2014, 15: 1347-1361

30 Shoaee S, An Z, Zhang X, et al. Charge photogeneration in polythiophene-perylene diimide blend films. Chem Commun, 2009, 27: 5445-5447

31 Chen Z, Lohr A, Saha-möller CR, et al. Self-assembled $\pi$-stacks of functional dyes in solution: structural and thermodynamic features. Chem Soc Rev, 2009, 38: 564-584

32 Kamm V, Battagliarin G, Howard IA, et al. Polythiophene: perylene diimide solar cells-the impact of alkyl-substitution on the photovoltaic performance. Adv Energy Mater, 2011, 1: 297-302

33 Shivanna R, Shoaee S, Dimitrov S, et al. Charge generation and transport in efficient organic bulk heterojunction solar cells with a perylene acceptor. Energy Environ Sci, 2014, 7: 435-441

34 Yan Q, Zhou Y, Zheng YQ, et al. Towards rational design of organic electron acceptors for photovoltaics: a study based on perylenediimide derivatives. Chem Sci, 2013, 4: 4389-4394

35 Lin Y, Wang Y, Wang J, et al. A star-shaped perylene diimide electron acceptor for high-performance organic solar cells. Adv Mater, 2014, 26: 5137-5142

36 Zhong Y, Trinh MT, Chen R, et al. Efficient organic solar cells with helical perylene diimide electron acceptors. J Am Chem Soc, 2014, 136: $15215-15221$

37 Sun D, Meng D, Cai Y, et al. Non-fullerene-acceptor-based bulkheterojunction organic solar cells with efficiency over 7\%. J Am Chem Soc, 2015, 137: 11156-11162

38 Lee J, Singh R, Sin DH, et al. A nonfullerene small molecule acceptor with $3 \mathrm{D}$ interlocking geometry enabling efficient organic solar cells. Adv Mater, 2016, 28: 69-76

39 Zhong $\mathrm{H}, \mathrm{Wu} \mathrm{CH}, \mathrm{Li} \mathrm{CZ}$, et al. Rigidifying nonplanar perylene diimides by ring fusion toward geometry-tunable acceptors for high-performance fullerene-free solar cells. Adv Mater, 2016, 28: 951-958

40 Kozma E, Kotowski D, Catellani M, et al. Synthesis and characterization of new electron acceptor perylene diimide molecules for photovoltaic applications. Dyes Pigments, 2013, 99: 329-338

41 Cheng P, Zhao X, Zhou W, et al. Towards high-efficiency non-fullerene organic solar cells: matching small molecule/polymer donor/acceptor. Organic Electrons, 2014, 15: 2270-2276

42 Zhang X, Jiang B, Zhang X, et al. Cooperatively tuning phase size and absorption of near ir photons in P3HT: perylene diimide solar cells by bay-modifications on the acceptor. J Phys Chem C, 2014, 118: 24212-24220

43 Liu X, Luo G, Cai X, et al. Pyrene terminal functionalized perylene diimide as non-fullerene acceptors for bulk heterojunction solar cells. RSC Adv, 2015, 5: 83155-83163

44 Hartnett PE, Timalsina A, Matte HSSR, et al. Slip-stacked perylenediimides as an alternative strategy for high efficiency nonfullerene acceptors in organic photovoltaics. J Am Chem Soc, 2014, 136: 16345-16356

45 Cai Y, Huo L, Sun X, et al. High performance organic solar cells based on a twisted bay-substituted tetraphenyl functionalized perylenediimide electron acceptor. Adv Energy Mater, 2015, 5: $16345-16356$

46 Li C, Wonneberger H. Perylene imides for organic photovoltaics: yesterday, today, and tomorrow. Adv Mater, 2012, 24: 613-636

47 Fron E, Schweitzer G, Osswald P, et al. Photophysical study of bay substituted perylenediimides. Photochem Photobiol Sci, 2008, 7: 1509-1521

48 Guide M, Pla S, Sharenko A, et al. A structure-property-perfor- 
mance investigation of perylenediimides as electron accepting materials in organic solar cells. Phys Chem Chem Phys, 2013, 15: 18894-18899

49 Qiu W, Chen S, Sun X, et al. Suzuki coupling reaction of 1,6,7,12tetrabromoperylene bisimide. Org Lett, 2006, 8: 867-870

50 Huo L, Liu T, Sun X, et al. Single-junction organic solar cells based on a novel wide-bandgap polymer with efficiency of $9.7 \%$. Adv Mater, 2015, 27: 2938-2944

51 Chen W, Yang X, Long G, et al. A perylene diimide (PDI)-based small molecule with tetrahedral configuration as a non-fullerene acceptor for organic solar cells. J Mater Chem C, 2015, 3: 4698-4705

52 Sun Y, Seo JH, Takacs CJ, et al. Inverted polymer solar cells integrated with a low-temperature-annealed sol-gel-derived $\mathrm{ZnO}$ film as an electron transport layer. Adv Mater, 2011, 23: 1679-1683

Acknowledgments This work was supported by the National Natural
Science Foundation of China (51473009 and 51273203), and the Fundamental Research Funds for the Central Universities (YWF-14-HHXY-007 and YWF-14-HXXY-014).

Author contributions Cai Y performed the experiments for organic solar cells and wrote the draft. Guo X synthesized the organic compounds. Sun $\mathrm{X}$ conceived the experiments, analyzed the results and wrote the paper. Wei D and Yu M provided theoretical simulation. Huo L analyzed the results. All authors contributed to the general discussion and revised manuscript.

Conflict of interest The authors declare that they have no conflict of interest.

Supplementary information Supplementary data: the TGA thermogram, the calculation for the Dihedral angles of the optimized geometry of TN-PDI, the absorption features of donor-acceptor blends, the SCLC measurement for the electron mobility of TN-PDI and the mobility of optimized device are available in the online version of this paper.

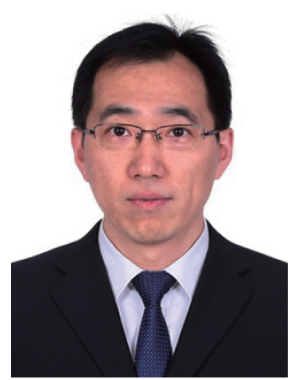

Xiaobo Sun received his BSc and MSc degrees in materials science from Jilin University, and $\mathrm{PhD}$ degree in chemistry from the Key Laboratory of Organic Solids, Institute of Chemistry, Chinese Academy of Sciences (ICCAS). Then, he joined Prof. Robert C. Haddon's group in the University of California at Riverside as a postdoctoral researcher (2006-2011). In 2012, he joined the School of Chemistry and Environment at Beihang University (Beijing, China) as an associate professor. His current research interests include organic photovoltaic materials and devices, and graphite based nanocomposites for electronic packaging.

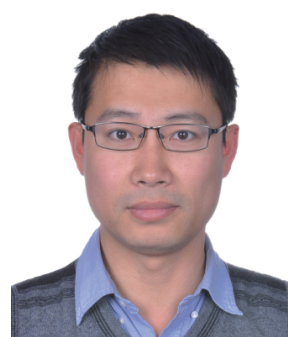

Yanming Sun is currently a professor at Beihang University. He received his BSc degree in chemistry from Shandong University and PhD degree in chemistry from the Key Laboratory of Organic Solids, ICCAS. In 2007, he became a research assistant at the University of Manchester, UK. Then, he joined Prof. Alan J Heeger's group in the University of California at Santa Barbara as a postdoctoral researcher (Jan. 2009-Aug. 2013). In 2013, he was awarded with the "Youth 1000 Talent Plan" and then joined in Beihang University. He has published more than 60 papers, including Nat. Mater., Nat. Commun., J. Am. Chem. Soc., Adv. Mater., Nano Lett., etc. His current research is focused on organic and polymer solar cells.

\section{构筑扭曲萠酰亚胺单分子型电荷受体材料用于高性能有机太阳能电池}

蔡芸皓 ${ }^{1}$, 郭谢友 ${ }^{1}$, 孙晓波 ${ }^{*}$, 魏东辉 ${ }^{2}$, 于明明 ${ }^{2}$, 霍利军 ${ }^{1 *}$, 孙艳明 $1^{*}$

摘要 近年来, 本体异质结型有机太阳能电池领域中, 菲酰亚胺类衍生物作为富勒烯类电荷受体材料的最佳替代材料而得到广泛关注. 很 多研究表明扭曲构型的分子结构设计可以明显地抑制萠酰亚胺的聚集行为. 本研究在萠酰亚胺的四个湾位同时共轭引入荎基官能团, 从 而合成一种简单结构的菲酰亚胺单分子型电荷受体材料TN-PDI. 四个共轭萘基的引入使菲酰亚胺平面骨架扭曲至 $33^{\circ}$. 分别以 TN-PDI和一 种宽带隙聚合物PDBT-T1为电荷受体材料和给体材料构筑本体异质结型有机太阳能电池, 其光电转换效率可达 $3.0 \%$. 研究结果表明, 四个 湾位同时共轭取代菲酰亚胺是一种制备简单高效蓷酰亚胺单分子型电荷受体材料的有效方法. 